\title{
THE SOLUTION AND PRECIPITATION OF IRON IN THE FORMATION OF IRON PAN.
}

\author{
By C. G. T. MORISON, M.A. AND D. B. SOTHERS, B.A. \\ School of Rural Economy, Oxford.
}

The formation of Iron Pan or Ortstein is of fairly frequent occurrence both in Britain and on the Continent of Europe. It is of some economic importance, for where it occurs considerable expense has to be incurred before it is possible to grow a crop of any kind on the soil. The Pan consists of a hard layer of material which has to be broken through for successful cultivation, as it is cemented together in such a manner as to prevent any penetration of plant roots and to limit the circulation of air and water.

It does not appear to be associated with any one physical soil type, although it is certainly commoner on soils containing much sand and coarse material, but formations of a similar character are to be found on soils of a heavier nature.

Associated with Pan formation are certain distinctive soil conditions. In the first place there must be an almost complete absence of calcium carbonate. This results in a considerable tendency for the accumulation of acid humus on the surface, the formation of which will be encouraged or hindered by position and facilities for drainage.

This humus layer varies from 5-20 cms. in thickness, and the most conspicuous plants associated with it are whortleberry and various heaths. Immediately beneath this humus covering lies a layer of sand from which most of the colouring matter has been removed, and which has been bleached in exactly the same way as a stone embedded in a peat bog has been bleached, owing to the removal of ferric hydroxide to which yellow sand normally owes its colour.

The other most important characteristic of this layer is its poverty in soluble mineral material. Many years' exposure to the liquid 
draining through the layers of peat on the surface have removed these bodies. This layer of bleached sand may vary in thickness from $5-60 \mathrm{cms}$.

At a certain depth, which probably varies with the level of the soil water in summer, there is a sudden change to the Pan proper. This may vary in thickness from 10 to $60 \mathrm{cms}$, the variation being probably caused by the amount of soluble material in the soil above.

The Pan consists of a hard mass quite impervious to water and to the roots of plants, and which varies in colour from yellowish-brown to black, according to the amount of organic matter which it contains. As the amount of organic matter decreases, the colour changes until the yellow brown of the ferric hydroxide becomes the dominant shade.

Analyses of various Pans are given in Table $I$.

These figures show conclusively that there is a great concentration of organic matter in the Pan and that of the soluble minerals the most important are iron, aluminium, and silicon.

There has been a great deal of work done on the subject, and various theories have been put forward to account for the formation of the Pan. A list of the more important contributions to the subject is given at the end of the present paper.

In the main the result of these papers is to put forward three distinct theories for the formation of Iron Pan, with which the names of Mayer, Faye, Münst, and Ramann, may be respectively connected.

The first of these theories is that which traces Pan formation to the alternate reduction and oxidation of iron humates in which the iron on the surface is reduced by the acid humus to the ferrous state dissolved as ferrous humate carried down to the subsoil, and there precipitated as ferric humate owing to oxidation by the air which at the dry season can readily penetrate to that depth.

The second explanation is that which is given in The Soil, A. D. Hall, in which it is supposed that the organic matter of the soil will reduce ferric oxide to ferrous oxide, and then that the carbon dioxide solution in the soil will cause its solution as ferrous bicarbonate, which is reconverted into ferrous carbonate at the Pan level, and probably later on oxidised to the ferric state.

Lastly the more modern papers on the subject consider the formation of Pan to be due to the formation of colloidal humus compounds of iron and aluminium, which are carried down into the soil, and are there precipitated by soluble salts, by loss of water, or by the change of bases.

It will be obvious in the course of this paper that the authors are 
in agreement with the last of these explanations, and it was largely because the experimental work on which these conclusions were based seerned in many cases unsatisfactory that they decided to re-examine the whole subject.

\section{TABLE I.}

1. Caesar's Camp.

\begin{tabular}{|c|c|c|c|c|c|}
\hline & & Bleached sand & Pan & Soil below & Pan \\
\hline & Hyg. moisture & $1 \cdot 27$ & 3.064 & .902 & \\
\hline & Loss on ignition ... & $1 \cdot 84$ & $7 \cdot 220$ & $1 \cdot 36$ & \\
\hline Soluble & $\mathrm{Fe}_{2} \mathrm{O}_{3}$ and $\mathrm{Al}_{2} \mathrm{O}_{3}$ & $\cdot 493$ & $4 \cdot 066$ & $3 \cdot 211$ & $\%$ \\
\hline in & 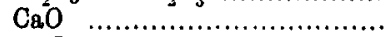 & $\cdot 0801$ & $\cdot 350$ & $\cdot 106$ & in \\
\hline hydro- & 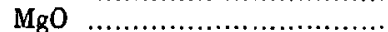 & .0632 & .0841 & .1105 & soil \\
\hline chloric & $\mathrm{P}_{2} \mathrm{O}_{5}$ & trace & .0366 & .0183 & \\
\hline acid & 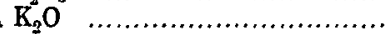 & $\cdot 0870$ & $\cdot 1546$ & $\cdot 1520$ & \\
\hline
\end{tabular}

2. Freudenstadt, Sehoarzuald.



3. Schwarzwald.

\begin{tabular}{|c|c|c|c|c|}
\hline $\begin{array}{l}\text { Soluble } \\
\text { in } \\
\text { hydro- } \\
\text { chloric } \\
\text { acid }\end{array}$ & 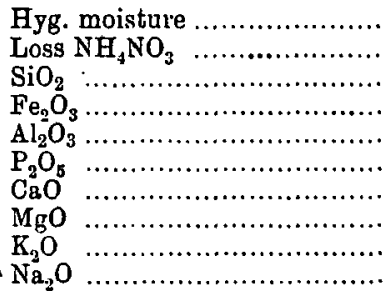 & $\begin{array}{l}\cdot 084 \\
\cdot 363 \\
\cdot 347 \\
\cdot 038 \\
\cdot 132 \\
\cdot 023 \\
\cdot 026 \\
\cdot 009 \\
\cdot 035 \\
\cdot 009\end{array}$ & $\begin{array}{r}1 \cdot 156 \\
3 \cdot 566 \\
1 \cdot 253 \\
1 \cdot 811 \\
1 \cdot 426 \\
\cdot 154 \\
\cdot 029 \\
\cdot 049 \\
\cdot 184 \\
\cdot 019\end{array}$ & $\left.\begin{array}{l}\cdot 341 \\
\cdot 813 \\
\cdot 647 \\
\cdot 592 \\
\cdot 695 \\
\cdot 092 \\
\cdot 025 \\
\cdot 022 \\
\cdot 108 \\
\cdot 016\end{array}\right)$ \\
\hline
\end{tabular}

4. Schwarzwald.

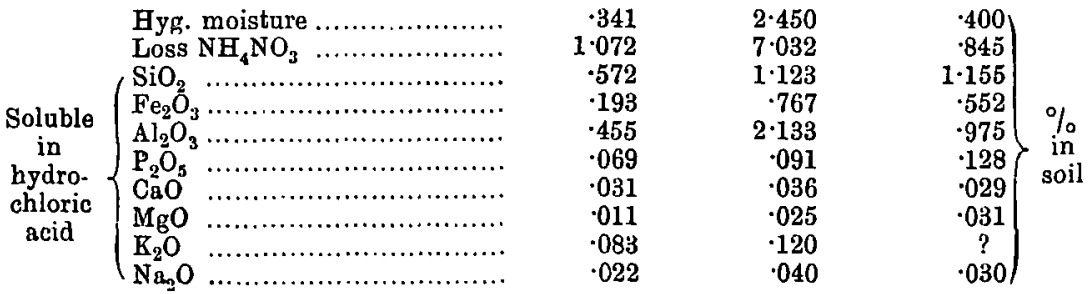

Analyses 2, 3 and 4, Münst, Abstract in Zentralblatt für Agrikulturchemie, Jan. 1912.

It having been the custom to regard iron as being the effective agent in forming the Pan, and as most of the explanations of this action revolve round alternate reduction and oxidation of iron compounds, it 
was decided to investigate these bodies. The delicacy of the colour reactions of the ferrous and ferric ion offers facilities which are not forthcoming in the case of aluminium. It was only at the close of this investigation that it became apparent that aluminium plays a no less important part than iron in the formation of the Pan.

The experimental work has been mainly concerned with the investigation of the properties of various so-called humates and with attempts to dissolve iron either as ferrous humate or as ferrous bicarbonate under conditions which approximate to those which naturally occur.

It was also hoped to obtain some information as to the way in which iron so dissolved was precipitated to form the Pan.

Various humates were prepared in the way recommended by Mayer, which consists in adding to humic acid, dissolved in the least possible quantity of alkali, solutions of salts of the desired metals. In this way ferrous, ferric, and calcium humate were prepared, and the precipitates obtained were subjected to prolonged washing. In each case the precipitates were not entirely insoluble, but gave solutions containing both the base and organic matter.

The terms humates and humic acid are used by the authors purely for the sake of convenience, and they do not wish to express an opinion as to their existence or otherwise.

It is entirely unimportant, from the point of view of the present work, whether so-called acid humus contains a definite acid, or whether it is a colloidal absorption complex showing some of the reactions associated with acids.

After 5 days' washing, the filtrate from the ferrous humate still gave deep blue colorations with ferricyanide. After the same period, the washings from the ferric humate also gave a deep coloration, although all traces of chloride from the ferric salt employed had long disappeared. It therefore appears that ferric humate cannot be prepared pure by the above method, and that ferrous humate is to a certain exteut soluble, and that the solution is capable of giving ferrous reactions.

The question of the method of solution and consequent precipitation of the irun was next investigated.

It is stated by Miyer that perfectly healthy soils, provided that organic matter be present, will give the reaction of ferrous iron with potassium ferricyanide when boiled with dilute hydrochloric acid. This was tested by boiling a little healthy soil with hydrochloric acid in the presence of peat. A strong reaction of ferrous salts was obtained. 
As solutions containing ferrous iron may be extracted from peat itself by the action of hydrochloric acid, the experiment was repeated, the peat being replaced by peat which had already been boiled with hydrochloric acid and then well washed. Again the reaction for ferrous salts was obtained. A little of this purified peat was then shaken with a solution of ferric chloride. Reduction commenced irnmediately, even in the cold. The first experiment was then repeated, the hydrochloric acid being replaced by sulphuric acid, citric acid, ammonium chloride, ammonium oxalate, ammonium carbonate, potassium chloride, and sodium chloride. In the first three cases the ferrous reaction was easily obtained. With the ammonium salts of weak acids, brown solutions incapable of being tested were obtained. With potassium chloride there was a very slight reaction: with sodium chloride, and with a simple mixture of peat and soil, no reaction was obtained.

TABLE II.
$\%$ ammoniacal nitrogen
I. Peat
(i) .004395
II. Peat, deep Irish bog
(ii) $\cdot 004547$
III. Peat, medium depth Irish bog
(i) .003860
(ii) $\cdot 004307$
IV. Acid humus from surface of Pan......
(i) 01162
(ii) $\cdot 01123$
(i) $\cdot 0004297$
(ii) $\cdot 0004676$
V. Acid humus from surface of Pan......
(i) $\cdot 001108$
(ii) 001106
(iii) $\cdot 001108$

The experiments were then repeated with the substitution of precipitated ferric hydroxide for the soil. The results obtained in each case were exactly similar.

A still further set of experiments was made using as a source of iron the mineral limonite very finely ground. In this case the effect of the presence of carbon dioxide and peat was investigated both under ordinary conditions and under sterile conditions obtained by the addition of 1 c.c. of chloroform to each bottle.

The details of the experiment are not given, as there was no solution of ferrous compounds in any case.

These experiments seemed to prove that though the peat had a strong reducing action on any iron salts present, it had no direct action on ferric oxide itself, unless some body capable of bringing small quantities of iron into solution were present. 
The experiments further show that the usual methods of determining whether ferrous salts are present in a soil-i.e. by extracting with some strong acid-are quite useless if organic matter is present. Further work is in progress on this subject.

As ammonium chloride was by far the most efficient salt in bringing about the reaction described above, it seemed possible to the authors that ammonium salts present in the peat might play some part in aiding the solution of ferric oxide of the soil previous to its reduction to ferrous compounds.

The following determinations of ammoniacal nitrogen in peat and acid humus were therefore made, after the method described by Russell.

The ammoniacal nitrogen is in most cases very many times greater than that found in ordinary soils.

Litre bottles were then taken and filled with the following solutions :

(1) Precipitated ferric hydroxide and 750 c.c. distilled water, saturated with carbon dioxide.

(2) Precipitated ferric hydroxide and 750 c.c. distilled water, and the humic acid prepared from 15 gms. of peat.

(3) Precipitated ferric hydroxide and 750 c.c. water, saturated with carbon dioxide and humic acid as in (2).

(4) Entirely similar to (3).

(5) 100 gms. soil containing iron, 20 gms. peat washed free from ferrous salts, $1 \mathrm{gm}$. ammonium chloride and 750 c.c. carbon dioxide water.

(6) Similar to (5) with the omission of ammonium chloride.

The bottles, with the exception of number 4, were placed in a mechanical shaker. No. 4 was placed in a thermostat at $18^{\circ} \mathrm{C}$.

The bottles were removed from time to time. 25 c.c. were removed, filtered, and examined for the presence of ferrous iron.

No trace of ferrous iron was found after 1, 2, and 3 weeks.

Bottles 3 and 4 were then also placed in a thermostat at $20^{\circ} \mathrm{C}$. with an addition of 1 gramme of ammonium chloride to 4 , and all were examined after 5 days with the same negative result.

In this way it was shown that no iron is dissolved in the form of the ferrous ion, and that if it is removed in the form of a ferrous humus compound that compound is unlike the one prepared in the experiment already described which gave continually the reaction of ferrous iron.

1 Journal of Agricultural Science, Vol. III. 
The solution from bottle 5 was examined by boiling with dilute potassium hydroxicle to determine whether all the added ammonium chloride had been absorbed by the soil, and it was found that there was a considerable quantity in solution. At the same time a brown precipitate was obtained. This precipitate was dissolved in boiling dilute hydrochloric acid, and tested with a solution of ammonium sulphocyanide for the presence of ferric iron.

A faint red colour was ubtained. If the precipitate was dried and ignited and then dissolved in dilute hydrochloric acid, and if it were allowed to stand for some time in contact with the concentrated acid, the reaction was much more intense.

A similar precipitate but smaller in quantity was obtained from bottle 6 .

The solution from bottles 2,3 , and 4 gave no precipitate with potassium hydroxide, but the solution on evaporation and ignition, and subsequent solution in hydrochloric acid, gave the characteristic red colour with ammonium sulphocyanide.

On evaporating liquid from the bottles 1-6, that from 6 was the only one to give a precipitate with increasing concentration, which was shown to consist of ferric hydroxide. If the precipitate be filtered off and the filtrate again evaporated, a residue is obtained similar in kind to that obtained from the other bottles. It consisted of a brown sticky substance sometimes resoluble in water and sometimes not, with no apparent regularity.

On ignition of this residue ferric iron was found to be present in all cases, but most abundantly in 6, 5, and 2 .

It appears from these results

(1) That ammonium chloride has no effect in bringing into solution any iron in the form of either the ferrous or ferric ion; but that in bottles 5 and 6 of the last experiment the amount of iron in solution has been in some way affected.

(2) The iron, though apparently in solution, gives none of the reactions of the ferrous or ferric ion, consequently it is either part of a complex ion or it is present in an iron humus compound in the form of a colloid sol.

The following experiments were made in the hope that some comparison of the actual amount of iron removed might be made.

(1) Washed peat, 75 gms. soil, 750 c.c. of distilled water saturated with carbon dioxide. 
(2) Similar to (1).

(3) Washed peat, 75 gins. soil, 750 c.c. carbon dioxide water, $0.5 \mathrm{gm}$. ammonium chloride.

$(4,5,6)$ Similar to (1), (2) and (3) with the soil in each case replaced by precipitated ferric hydroxide.

In these cases the soil used was the subsoil from the Freudenstadt Pan.

Bottles 2 and 4 were placed in a thermostat at $35^{\circ} \mathrm{C}$., the others were left at the room ternperature. At definite intervals 25 c.c. solution were filtered off, evaporated, ignited, and dissolved in hydrochloric acid. The solution was then compared with a solution containing a known quantity of ferric iron, 5 c.c. of an ammonium sulphocyanide solution being added to each. Equal volumes were taken in each case and placed in similar glass cylinders. The standard solution was then added from a burette until approximately the same tint was reached. The standard solution contained $00085 \mathrm{gm}$. ferric iron per c.c. and the results below are expressed in c.c. of standard solution.

$\begin{array}{lccc} & \text { After } 7 \text { days } & 14 \text { days } & 21 \text { days } \\ \text { 1. } & 0.33 & 0.30 & 0.30 \\ 2 . & 0.15 & 0.16 & 0.20 \\ 3 . & 0.30 & 0.25 & 0.30 \\ 4 . & 0.12 & 0.20 & 0.18 \\ 5 . & 0.10 & 0.12 & 0.10 \\ 6 . & 1.04 & 1.40 & 1.50\end{array}$

The results are left expressed as c.c. of standard solution, as, although attempts were made, this colour method seemed too inaccurate for the determination of sinall amounts of iron, for the results, obtained by using different stiandard solutions, showed very little agreement.

Although it is impossible to place reliance on the above figures as representing the amounts of iron removed, there are some interesting points to be noted in connection with thein. Both in this and in the earlier experiments the amount of iron removed in the case of the mixtures kept at higher temperatures is the lowest, which is what would be expected if the solution is in reality a colloidal suspension.

The amount of iron in five cases out of the six is of the same order, while in the last bottle it is many times greater. Thus ammonium chloricle, while it has no effect on the amount of iron removed from the soil, considerably increases the amount dissolved if ferric hydroxide be substituted for the soil.

As the soil in the above experiments was the normal sand from Freudenstadt it is quite reasonable that this which had been for some 
time air dry should be more resistant than freshly precipitated ferric hydroxide.

It is possible to explain the increase caused by ammonium chloride as being due to the formation of ferric hydroxide sol. It is well known that the sol only exists in the presence of small quantities of ferric chloride, which may be formed owing to the hydrolysis of the ammonium chloride. The observed increase may be either due to the ferric hydroxide sol itself or to au increase in case of formation of ferric humate sol.

It will be observed that the results do not agree with the results which were obtained previously. In bottles 5 and 6 of the earlier series of experiments it was found that an addition of ammonium chloride caused a diminution in the total amount of the iron removed. The explanation of this fact probably is connected with the nature of the soil which was employed. The authors at that period of their investigation, having no sample of sand from a Pan formation, used as a source of iron a red Devonshire soil which happened to be in their possession and which seemed to be most suitable. It represented a soil in a high state of fertility, and consequently on shaking with a saturated solution of carbon dioxide and ammonium chloride, a considerable amount of various materials would be dissolved. This solution would be a comparatively concentrated one, and the formation of the various sols would proceed with some difficulty.

The authors therefore regard the great difference between the amount of soluble material in the Freudenstadt sand and the Devon soil as explaining the result which was obtained with the latter.

According to Tacke and Suchting ${ }^{1}$, metallic iron dissolves in the presence of peat and water with evolution of hydrogen. It seemed of interest to repeat this experiment and further to investigate the state of combination of the iron that had been attacked. A mixture of peat, distilled water, and pure iron filings, was heated on the water bath. Hydrogen was evolved in fairly large quantities. After some time the liquid from the mixture was filtered off. A, solution was obtained giving a strong ferrous reaction with potassium ferricyanide, and resembling in every way the solution of ferrous humate described above.

A portion of this solution was then oxidized by being gently warmed with hydrogen peroxide. A slight brownish precipitate was obtained, and was filtered off. The solution was tested both with

1 Landwirtsch. Jahrbuch. 1911, p. 717. 
potassium ferricyanide and ammonium sulphocyanide, but neither ferrous nor ferric iron could be detected. If, however, a portion was evaporated to dryness, ignited, and re-dissolved in hydrochloric acid, the ferric reaction was at once given. The precipitate, either on standing with concentrated hydrochloric acid, or on ignition and solution in dilute acid, also gave a distinct ferric reaction.

It appears, therefore, from the similar behaviour of the solution obtained from the bottles and that obtained by the oxidation of ferrous humate, that the same compound is present in each case. Whether this solution is a colloidal solution of true ferric humate, or a colloidal absorption complex of colloidal humus and colloidal ferric hydrate, such as Baumann ${ }^{1}$ and Gully consider to be formed in all so-called humates, is not quite clear.

Finally, 250 c.c. of the solution in bottle 3 of the last series containing peat, soil, and ammonium chloride, were evaporated to dryness on the water bath. The residue obtained was only very slightly soluble in water. The residue was strongly ignited and weighed. It was then dissolved in hydrochloric acid and analysed. It consisted mainly of iron, aluminium and calcium, with slight traces of magnesium.

$$
\begin{aligned}
& \text { Total weight of ash...... } \quad 0260 \mathrm{gm} \text {. } \\
& \mathrm{Fe}_{2} \mathrm{O}_{3} \text { and } \mathrm{Al}_{2} \mathrm{O}_{3} \ldots \ldots . . .0092 \text {, }
\end{aligned}
$$

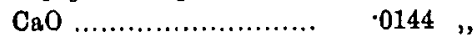

From these experinents the following conclusions may be drawn:

I. That peat is a strong reducing agent, but is not capable of reducing ferric oxide to ferrous oxide. The facts therefore seem in disagreement with the theory of Faye.

II. That the solution obtained by the action of peat on ferric oxide does not contain ferrous humate, which appears to be accompanied by the presence of ferrous ions. It therefore seems that Mayer's theory of the formation of Iron Pan is not correct.

III. That peat in the presence of water removes considerable quantities of minerals, especially ferric oxide, aluminium oxide, and calcium oxide, from the soil as colloidal suspensions. These colloid sols do not seem very sensitive to changes in concentration. Evaporation to dryness, however, destroys, at any rate to a certain extent, their capacity for suspension.

1 "Mitt. d. K. Bayr. Moorkulturanst." 3. (52-123), abstract in Jahresbericht ilber... Agrikultur Chemie, 1909, xI. p. 52. 
IV. That in the case of iron, the compound formed is probably ferric humate, but possibly an absorption complex of colloidal humus and colloidal ferric hydroxide.

As a result of the above experiments the authors believe that none of the previous theories completely represents the conditions obtaining during the removal of iron, and they put forward the following as being the most probable course of events.

One of the first results of the accumulation of the surface layer of peat is the production of substances showing acid properties.

The first action of these will be to remove the constituents of the soil which are more readily attacked. These are probably in the state of true solution. At the same time there are formed colloidal humates of iron, aluminium and calcium.

Owing to the fact that at the commencement the solution in the soil is comparatively of high concentration, these colloids are probably in the gel form. They do not assume the sol form until the concentration of the solution is much lower.

This would explain the fact that Pan formation is more common on sandy soils than on clays. The latter containing much more soluble material, owing to their composition and their large surface development, hinder the formation of the sol condition of these colloids and consequently the materials which form the Pan are not removed from their old position.

As soon then as the formation of these sol forms is possible, the iron and the aluminium and the calcium will be removed from the layer of what ultimately becomes bleached sand. Probably they are removed in the order calcium, aluminium, iron, as from the authors' experiments the concentration of ferric humate sol is smaller than calcium humate sol. This ferric humate may be formed by direct union of humic acid and ferric hydrate, or by the precipitation by ferric hydrate of solutions of other humates; such as the calcium salt. In the presence of ammonium chloride small quantities of ferric hydrate sol might be formed which would probably assist both reactions.

In the preparation of humates described above, the fact that as the wash water removed more and more salts so the humate gel tended to pass into the humate sol, lends support to the above.

It is just worth remarking here that the sol form of this particular colloid seems to be remarkably stable. Coagulation with electrolytes only occurs with great difficulty, and boiling does not 
alway's appear to bring about this result. Further investigations are also contemplated on this subject.

The authors then believe that as the concentration diminishes, ferric humate and the other colloidal humates tend to pass into the sol form. This is what is occurring throughout the wetter season of the year.

As the soil dries up and the water recedes from the surface, the major part of the colloidal suspension is taken with it, the water becomes more concentrated with respect to the colloid, and a small amount of the colloidal humate will be left behind in what will ultimately become the bleached sand layer.

When the desiccation process has progressed still further to a point about the level of the permanent water table in the soil, then the amount of ferric humate deposited will be larger.

The great bulk of the sol will have accumulated at this level and, owing to the negligible osmotic pressure of the colloid sol, it is certain that very little diffusion will take place throughout the mass of soil water with which it is now in contact. Consequently the process of desiccation will be much more rapid than diffusion, bringing about a deposit of practically the whole of the material which was in suspension.

The condition of affairs at the end of the wet season is then briefly this, that throughout the layer to be converted into bleached sand there is a small amount of ferric humate and a considerable deposit of it at a lower level just above the permanent water table.

As soon as the deposit at this level exists at all, it is easy to imagine the rapid manner in which it will increase, and it is not difficult to conceive of the actions described going on from year to year until the result that is called Iron Pan is reached.

On the arrival of the wet season again the coagulated and desiccated colloids will not entirely go back into suspension, as the colloid character may well have been changed during the process of desiccation.

It is also probable that oxidation plays a part in establishing the stability of the Pan. The air in summer will have comparatively free access down to the level at which the Pan is formed. Oxidation cannot affect ferric iron, but it will affect the humic acid, which will be partially oxidized; some of it will be converted into carbon dioxide and water, some will be left behind as a residue which is richer in oxygen than the original humic acid.

As time goes on the oxidation will proceed further and further till most of the irou will be left in the form of ferric hydroxide.

1 Mayer, Landwirtschaft. Versuchstat. 
The original humic acid of the bleached sand represents, as it were, one year's deposit, and is not subjected to prolonged oxidation in that position, being gradually transferred to the Pan layer.

In the presence of ammonium chloride it is also possible to get small quantities of ferric hydrate sol formed. This may play some part in the removal of iron. The same cycle of reactions would occur with this as with any other colloid sol. This is the only effect due to ammonium salts at ordinary temperatures of which any evidence was obtained.

It is conceivable that some of the iron bacteria may play a part in the formation of Pan. During the summer they will be most active at the level of the Pan, because that will be the only layer which will hold enough moisture for their existence.

It is possible that, in the absence of much organic matter, organisms might use the humic acid combined with the iron as a source of energy, and leave the iron in the form of ferric hydroxide. The authors, however, consider that it is possible to account for the formation of $\mathrm{Pan}$ without the intervention of living organisms. They are in complete agreement with the conclusions of Münst with regard to the rôle of colloidal humates, and would only emphasize the probable importance of iron as well as aluminium.

In conclusion, the authors wish to thank Sir William Schlich, F.R.S., for having very kindly obtained for them eight samples of material, four from Freudenstadt and four from Cooper's Hill.

\section{BIBLIOGRAPHY.}

MLuLder. Chemie der Ackerkrume.

FaYe. Comptes Rendus, 1870, LXXI. 1. 245.

Emeis. Waldbauliche Forschungen (Berlin, 1876).

RAMANN. Bodenkunde.

Moller. Die naturlichen Huniusformen (1887).

MAYER, A. Versuchstut. 1903, 58. p. 161.

Zimmermane, K. v. Bildung des Ortsteins (Leipzig, 1904).

SAUER. Zeitschr. f. prakt. Geologie, xvIr. p. 527.

Ehrenberg. Zeitschr. f. Forst. und Jagdw. 1909, p. 177.

A LBert. Zeitschr. f. Forst. und Jagdw. 1910.

Münst. Ortsteinstudien. Mittlz. d. geol. Abt. d. k. württ. Statist Landesantes, 1910.

LEMENGeN Westerbury. Ortstein bildung.

NikLas. Verwitterung der Silikate und der Gesteine.

Homberger. Versichstat. 73. 221.

MAYer. Fuhlings Landu. Zeitung. 1910, 315. 